\title{
In-Vitro Comparison of the Effect of XP-Endo Shaper and One-Shape Rotary Files on the Incidence of Root Dentin Cracks
}

\section{A Delvarani ${ }^{1}$,AA Moshary ${ }^{1}$, M Ghasemian Yadegari ${ }^{2}$, T Bitaraf $^{*}$ (iD) 3}

1- Assistant Professor, Department of Endodontics, Member Ship of Dental Material Research Center, Faculty of Dentistry, Tehran Medical Sciences,Islamic Azad University, Tehran, Iran

2-Dentist

3- Assistant Professor, Dental Implant Research Center, Dental Faculty, Tehran Medical Sciences, Islamic Azad University, Tehran, Iran

\section{ARTICLE INFO}

Article History

Received: August 2020

Accepted: Oct 2020

ePublished:NOV 2020

Corresponding author:

T Bitaraf, Assistant

professor, Dental Implant

Research Center, Dental

Faculty, Tehran Medical

Sciences, Islamic Azad

University, Tehran, Iran

Email: taherehbitaraf

yahoo.com

\begin{abstract}
Background and Aim: Root canal preparation with systems with the least chance of dentin cracking can increase the success of endodontic treatment. This study aimed to compare the One-Shape and XP-endo Shaper rotary files in the dentin crack incidence in the mesiobuccal canals of mandibular first molars.

Materials and Methods: In this experimental study, 60 eligible extracted mandibular first molars were randomly divided into three groups. The roots were prepared to \#30 and 4\% taper in the XP-endo Shaper group and \#25 and 6\% taper in the One-Shape group. The control samples were left intact. All groups were sectioned at 2, 4, and $6 \mathrm{~mm}$ from the apex and examined under a stereomicroscope at $20 \times$ magnification. The incidence, location, and type of cracks were analyzed using chi-square test.

Result: There were no cracks in the controls. The crack percentage was $23.33 \%$ $(n=14)$ and $11.66 \%(n=7)$ in the One-Shape and XP-endo Shaper groups, respectively, with a significant difference with crack-fee samples. There was no significant difference between One-Shape and XP-endo Shaper systems in the three sections $(\mathrm{P}>0.05)$. In the $2 \mathrm{~mm}$ section, cracks were observed in six sections (10\%) with One-Shape and four sections $(20 \%)$ with XP-endo Shaper. In the $4 \mathrm{~mm}$ section, cracks were observed in one section (5\%) with One-Shape and five sections (25\%) with XP-endo Shaper. In the $6 \mathrm{~mm}$ section, cracks were observed in seven sections (35\%) with One-Shape and one section (5\%) with XP-endo Shaper.

Conclusion: The One-Shape and XP-endo Shaper systems were similar in crack incidence in the mesiobuccal canal of mandibular first molars.

Keywords: Tooth Fractures, Root Canal Preparation, Mandible, Molar
\end{abstract}

J Res Dent Maxillofac Sci 2020;5(4):31-36 DOI: 10.29252/jrdms.5.4.31

\section{Introduction:}

Root canal preparation with nickel-titanium (NiTi) rotary files may potentially cause dentin cracking. Root fractures may occur following microcracks or hairline tooth fractures that are exacerbated by occlusal pressures. ${ }^{(1-5)}$ These fractures are one of the problems in root canal treatment, which often leads to tooth extraction. ${ }^{(6)}$.

In the last two decades, various manufacturers have introduced many new rotary files; however, some aspects of these systems, such as the cleaning ability, stress accumulation, and the inability to adequately prepare oval-shaped canals, are still debated. ${ }^{(1)}$ Kim et al found a potential link between the design of NiTi files and the likelihood of longitudinal root fractures. ${ }^{(7)}$ Much research has been done on comparing different files of manual or rotary systems in the incidence of root dentin cracks, and it has been shown that both systems cause root dentin cracks. ${ }^{(5)}$

One-Shape (Micromega, Besancon, France) is a new system of NiTi files that prepare the canal by using a single file with continuous rotation ${ }^{(8)}$ One-Shape files work well in highly curved canals. One of the unique advantages of these files is their simplicity and anti-fracture control, which deforms the file before it is broken and opens the screws, adapting to the curvature of the canal. With this system, root canal treatment is completed four times faster compared to conventional methods. ${ }^{(9-13)}$

New XP-endo Shaper files (XPS; FKG Den- 
taire, La Chaux-de-Fonds, Switzerland) have recently been released. The XP-endo Shaper system is an innovative shaping tool and the tool of choice for treating most canals. ${ }^{(9)}$ It has met the need for three-dimensional (3D) canal cleaning and less invasive treatments. Good thermal adaptation, superelasticity, and resistance to fatigue and rotational pressures characterize these files. Also, there is no need for aggressive treatments with XP-endo Shaper files. ${ }^{(14)}$ Uğur Aydın et al examined the XP-endo Shaper file with Reciproc Blue and WaveOne gold for the incidence of canal wall cracks and reported that none of the three files forms or spreads dentin cracks in the root. ${ }^{(15)}$ Liu et al showed that self-adjusting files (SAF) and Reciproc files formed fewer cracks than ProTaper and One-Shop files. ${ }^{(5)}$ The frequency of dentin cracking due to the use of XP-endo Shaper files compared to One-Shape files has been investigated in a few studies. The present study aimed to evaluate the incidence of dentin cracking after the mesiobuccal canal preparation of mandibular first molars using two systems: XP-endo-Shaper and One-Shape.

\section{Materials and Methods:}

This experimental study was performed in vitro using a stereomicroscope (SMZ 1000, Nikon, Japan). Sixty eligible teeth were randomly divided into three groups ( $n=20$ in each group) of control, XP-endo Shaper, and One-Shape using block randomization.

Extracted mandibular molars with closed apices, without crown and root cracks or fractures, with intact roots, and without root caries or external resorption were collected and placed in a $5.25 \%$ sodium hypochlorite $(\mathrm{NaOCl})$ solution for one hour to be disinfected and were kept in saline until study. Radiographs were taken from each tooth in buccolingual and mesiodistal directions, and according to Schneider's method, teeth with root curvatures between 20 and 35 degrees were selected. ${ }^{(10,11)}$ Teeth with previous root canal treatment, canal calcification, or internal resorption were excluded. Teeth were examined under a microscope at $20 \times$ magnification for cracks in the apical area of the root, and specimens with cracked roots were excluded. ${ }^{(16-18)}$ Then, an access cavity was prepared in the teeth. By placing two \#8 or \#10 K-files (Maillefer, Dentsply,
Ballaigues, Switzerland) in the canal simultaneously and observing their passing from the root end, it was ensured that the canal path was open and there were separate mesiobuccal and mesiolingual canals. Teeth without these features were excluded. Then, a \#15 K-file was inserted into the mesiobuccal canal, and the impossibility of passing the file through the apex was checked, thus matching the apical diameter of the canal. Teeth without these conditions were also excluded.

The root length of the teeth was measured from the cervical area to the apex, and the roots of the same length were maintained. The length of the teeth was equalized by shortening the crown such that all the teeth were $14 \pm 1 \mathrm{~mm}$ long. Finally, 60 eligible teeth were included in the study, and the mesial root was separated from the distal root along with its crown using a bur. ${ }^{(3)}$

The coronal parts of the canals were passively widened using \#3 and \#4 Gates Glidden drills (Dentsply, Maillefer, Ballaigues, Switzerland). (3) The samples were then randomly divided into three groups.

For each of the samples, the working length was determined by placing a \#10 K-file in the mesiobuccal canal and observing its tip in the apex and reducing its length by one millimeter. Then, the canals were prepared to \#15 K-file. In each of the One-Shape and XP-endo Shaper groups, the canals were prepared according to the manufacturer's instructions. Canal preparation in One-Shape groups was performed using a speed and torque control motor (X Smart, Dentsply Maillefer, Ballaigues, Switzerland) at a speed of 350 to 450 revolutions per minute (rpm), a minimum torque of $2.5 \mathrm{Ncm}$, and size \#25. ${ }^{(19)}$

In XP-endo Shaper groups, the canals were prepared using the control motor (X Smart, Dentsply Maillefer, Ballaigues, Switzerland) and by adjusting the motor to full rotation at a speed of 800 to $1000 \mathrm{rpm}$, a torque of $1 \mathrm{Ncm}$, and size \#30. In all groups, after each entry of the file into the canal and three times of free movement (passive), the canal was rinsed with $2 \mathrm{ml}$ of a $2.5 \% \mathrm{NaOCl}$ solution using a syringe with a 27 -gauge needle head (Max-i-Probe, Dentsply-Rinn, Elgin, IL). A \#10 K-file was used to control the patency of the canal path. The roots were then cut horizontally at 2, 4, and $6 \mathrm{~mm}$ from the apex using a handpiece and a disc (D \& Z, Wellington, New Zealand) 
with a thickness of $0.20 \mathrm{~mm}$ under cold water. Then, the pieces were viewed under the stereomicroscope at $20 \times$ magnification, and the images were recorded by the attached camera (SMZ 1000, Nikon, Japan). The presence of root dentin cracks and their type based on their completeness or incompleteness were examined separately by two coordinated and experienced endodontists and were recorded. Due to disagreement between the two, another endodontist examined the disputed samples, and two identical opinions from the three viewpoints determined the result. In all groups, each rotary file was used to prepare four canals, and in each session, five canals were prepared so that the operator's fatigue did not make a difference between the first and the last samples. Stereomicroscopy and completion of information forms were used to collect data.

The minimum sample size required for each study group was calculated to be 20 according to a study by Soni et al, ${ }^{(20)}$ using the option of Tests for Two Ordered Categorical Variables and PASS software, considering $\propto=0.05, \beta=0.2$, and effect $s i z e=0.23$. The results were statistically analyzed using chi-square test with SPSS (version 22; SPSS Inc., Chicago, IL, USA) with an error of 0.05 .

\section{Results:}

The findings were evaluated in two case groups and one control group in a total of 180 sections and are shown in Tables 1 to 3 . There was no crack in the control group (Figure 1-a). The percentages of root dentin cracks were $23.33 \%(n=14)$ with the One-Shape system and $11.66 \%(n=7)$ with XP-endo Shaper i.e. both systems caused cracks, but the samples with cracks in both systems were significantly fewer than the samples without cracks. There was no significant difference between the two systems in terms of root dentin cracks $(\mathrm{P}>0.05)$. In terms of complete cracks, the XP-endo Shaper system did not form complete cracks in any of the sections (all cracks were incomplete). In the One-Shape group, 5\% of the samples ( 3 sections) had complete cracks and most cracks were at the $6 \mathrm{~mm}$ section and equal to the sum of cracks at the $2 \mathrm{~mm}$ and $4 \mathrm{~mm}$ sections. In the XP-endo Shaper group, the cracks were more frequent at the $4 \mathrm{~mm}$ section and equal to the sum of the $2 \mathrm{~mm}$ and $6 \mathrm{~mm}$ sections.
The comparison of the three sections between the One-Shape (Figure 1-b) and XP-endo Shaper (Figure 1-c) systems was made with Mann-Whitney test. There were no significant differences in the $2 \mathrm{~mm}$ sections $(\mathrm{P}=0.565), 4 \mathrm{~mm}$ sections $(\mathrm{P}=0.289)$, or $6 \mathrm{~mm}$ sections between the two systems $(\mathrm{P}=0.935, \mathrm{P}>0.05)$.

The comparison of the three sections in each system was made with Kruskal-Wallis test. There was no significant difference in the incidence of cracks at 2,4 , and $6 \mathrm{~mm}$ sections of roots prepared with the One-Shape $(\mathrm{P}=0.063)$ and XPendo Shaper $(\mathrm{P}=0.854)$ systems i.e. there was no significant difference in comparison of the three sections in terms of the number of cracks in each system $(\mathrm{P}>0.05)$.

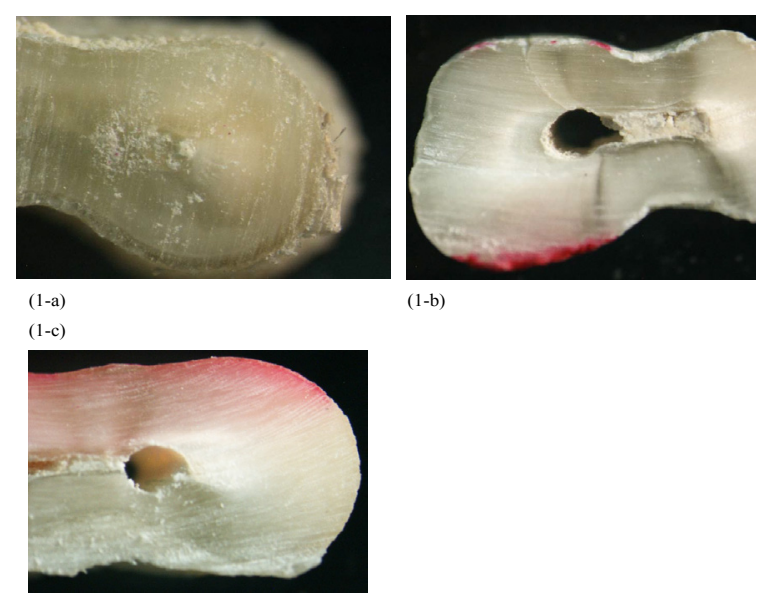

Figure 1: Sections under the stereomicroscope at $20 \times$ magnification. (1-a) the control sample with no crack, (1-b) the One-Shape system, and (1-c) the XP-endo Shaper system

Table 1: Distribution of samples according to the incidence of cracks by rotary file type in the $2 \mathrm{~mm}$ section

\begin{tabular}{|c|c|c|c|c|}
\hline \multirow{2}{*}{ Rotary file } & \multirow{2}{*}{ No } & \multicolumn{2}{|c|}{ Yes } & \multirow[b]{2}{*}{ Total } \\
\hline & & $\begin{array}{c}\text { Incom } \\
\text { plete }\end{array}$ & $\begin{array}{c}\text { Compl } \\
\text { ete }\end{array}$ & \\
\hline One-Shape & $\begin{array}{c}14 \\
70 \%\end{array}$ & $\begin{array}{c}5 \\
25 \%\end{array}$ & $\begin{array}{c}1 \\
5 \%\end{array}$ & 20 \\
\hline XP-endo Shaper & $\begin{array}{c}16 \\
80 \%\end{array}$ & $\begin{array}{c}4 \\
20 \%\end{array}$ & $\begin{array}{c}0 \\
0 \%\end{array}$ & 20 \\
\hline Chi-square test result & $\mathrm{P}=0.565$ & & & \\
\hline
\end{tabular}


Table 2: Distribution of samples according to the incidence of cracks in different root sections by rotary file type in the $4 \mathrm{~mm}$ section

\begin{tabular}{|c|c|c|c|c|}
\hline \multirow[t]{2}{*}{ Crack } & \multirow[t]{2}{*}{ No } & \multicolumn{2}{|l|}{ Yes } & \multirow[t]{2}{*}{ Total } \\
\hline & & $\begin{array}{l}\begin{array}{l}\text { Incom } \\
\text { plete }\end{array} \\
\end{array}$ & $\begin{array}{l}\text { Compl } \\
\text { ete }\end{array}$ & \\
\hline One-Shape & $\begin{array}{c}19 \\
95 \%\end{array}$ & $\begin{array}{c}1 \\
5 \%\end{array}$ & $\begin{array}{c}0 \\
0 \%\end{array}$ & 20 \\
\hline XP-endo Shaper & $\begin{array}{c}15 \\
75 \%\end{array}$ & $\begin{array}{c}5 \\
25 \%\end{array}$ & $\begin{array}{c}0 \\
0 \%\end{array}$ & 20 \\
\hline Chi-square test result & $\mathrm{P}=0.289$ & & & \\
\hline
\end{tabular}

Table 3: Distribution of samples according to the incidence of complete and incomplete cracks in different root sections by rotary file type in the $6 \mathrm{~mm}$ section

\begin{tabular}{lccccc}
\hline \multirow{2}{*}{ Rotary file } & Crack & No & \multicolumn{2}{c}{ Yes } & Total \\
\cline { 1 - 4 } One-Shape & & $\begin{array}{l}\text { Incomp } \\
\text { lete }\end{array}$ & $\begin{array}{l}\text { Compl } \\
\text { ete }\end{array}$ & \\
\hline XP-endo Shaper & 13 & 5 & 2 & 20 \\
\hline Chi-square test result & $65 \%$ & $25 \%$ & $10 \%$ & 20 \\
\hline
\end{tabular}

\section{Discussion:}

This study compared two rotary systems, the One-Shape and the XP-endo Shaper, in the crack incidence at 2, 4, and $6 \mathrm{~mm}$ distances from the apex in the mesiobuccal canal of mandibular first molars. Considering that these roots have a mesiodistal diameter smaller than the buccolingual diameter (such as the mesial root of mandibular molars, maxillary premolars, and mandibular anterior teeth), ${ }^{(21)}$ in this study, the mesiobuccal canals of mandibular first molars were used to compare the cracks formed with One-Shape and XP-endo Shaper systems. Many studies in this field have used mandibular anterior teeth ${ }^{(16,22,23)}$ or mandibular premolars. ${ }^{(3,24)}$ Some studies have also used mandibular molars to compare the incidence of dentin cracks, ${ }^{(1,15,18,25)}$, which highlights the importance of research on fractureprone canals. Therefore, the mesiobuccal canal of mandibular first molars was used in the present study.

In other studies in this field, canals without any curvature, ${ }^{(5,16,22,23,26)}$ with curvatures in the range of 25-40 degrees, ${ }^{(17,18)}$ or without reference to the degree of curvature ${ }^{(1,3,24)}$ have been used. Nevertheless, so far, no comparison has been made between the mesiobuccal canals of mandibular first molars in cracking after preparation with One-Shape and XP-endo Shaper files. Therefore, the results of this study can be valuable since it examined the mesiobuccal canals prepared with One-Shape and XP-endo Shaper files.

In the present study, no acrylic block or silicone impression material was used to simulate the periodontal ligament (PDL) during preparation. Some studies have suggested that the silicone layer allows limited freedom of movement. ${ }^{(27)}$ Soros et al stated that a flexible material can collapse and result in direct contact of the tooth with the acrylic cavity, whereas this does not occur in-vivo (with bone). ${ }^{(28)}$

In the present study, as in the study by Burklein et $\mathrm{al}^{(22)}$ the cracks were divided into two complete and incomplete groups.

Research has shown that no crack (complete and incomplete) was formed in the roots prepared with the XP-endo Shaper file. ${ }^{(15,25)}$ However, the present study showed that the XP-endo Shaper system caused incomplete cracks by $11.66 \%$ but did not cause complete cracks.

It has been reported that files made of M-wire and NiTi wires with controlled memory form fewer cracks because they are more elastic than other NiTi files. ${ }^{(29)}$ In the present study, the XPendo Shaper file with a higher elasticity formed fewer cracks than the One-Shape system.

Wilcox et al stated that the probability of root fracture increases with the amount of tooth structure removed. ${ }^{(29)}$ With a greater taper, more dentin is removed from the root and the likelihood of root fracture increases..$^{(17,29)}$

Uğur Aydın et al examined Reciproc Blue, XP-endo Shaper, and WaveOne gold files for canal wall cracks and found that none of the three files caused or spread root dentin cracks. ${ }^{(15)}$ In the present study, the XP-endo Shaper system caused incomplete cracking of $11.66 \%(\mathrm{n}=7)$ of the samples.

Aksoy et al examined XPS, Rb, and PTU files for root cracks after preparation and stated that no new dentin cracks were found in roots prepared with XPS and RB, but the PTU system increased the percentage of dentin cracks. ${ }^{(25)} \mathrm{How}-$ ever, in the present study, the XP-endo Shaper system caused incomplete root cracks in $11.66 \%$ 
of the samples.

Liu et al made a comparison among root canals prepared with Reciproc, One-Shop, ProTaper, and SAF in terms of dentin cracks. ${ }^{(5)}$ The $\mathrm{SAF}$ and Reciproc files formed fewer cracks than the ProTaper and One-Shop files $(\mathrm{P}<0.001) .{ }^{(5)} \mathrm{In}$ the present study, the XP-endo Shaper system caused fewer cracks than the One-Shape system. Burklein et al also reported more incomplete cracks with files with reciprocating motion, but no significant difference was observed between the PTU and WO systems in incomplete cracking $(\mathrm{P}>0.05) .{ }^{(22)}$

The results of the present study are in plain contrast to the results of some studies ${ }^{(15,25)}$ but are more similar to the study by Burklein et al in terms of the formation of more incomplete cracks than complete cracks. ${ }^{(22)}$

However, it is not yet clear whether incomplete cracks can become complete cracks after the completion of endodontic treatment or after the preparation of the post space or re-treatment. ${ }^{(29)}$ Simple masticatory forces and occlusal forces are also considered as factors for the development of dentin defects or fractures. ${ }^{(17)}$ Nevertheless, teeth without root canal treatment may also fracture. ${ }^{(22)}$

Uğur Aydın et al and Aksoy et al identified dentin defects similar before and after preparation with the XP file, meaning that the file did not cause any cracks in the root, which is contrary to the present study. ${ }^{(15,25)}$ The reason for this difference could be that the roots were not examined for cracks before preparation, and each of the cracks recorded may have been present in the canal wall before preparation ${ }^{(15,25)}$ although no cracks were observed in the control group.

Although sectioning the samples with a disc may cause cracks, no cracks were observed in the control group.

$\mathrm{Li}$ et al stained the samples with a methylene blue solution before preparation to identify cracks, which is a positive aspect of the cited study. ${ }^{(17)}$

In the present study, it was difficult and timeconsuming to section 60 teeth and image $180 \mathrm{sec}-$ tions by the stereomicroscope, and the degree of dentin hardness, which may play a role in root dentin cracking, was not evaluated. It is recommended to use new methods, such as micro-com- puted tomography (micro-CT), optical coherence tomography, or infrared thermography (limitation due to the size of the equipment) in the future to eliminate the sectioning stage. ${ }^{(30)}$

\section{Conclusion:}

Based on the findings of this study, both OneShape and XP-endo Shaper systems significantly increased the number of cracks in all samples. The difference between the two systems was not significant. In the One-Shape group, the cracks were more frequent in the coronal area, while in the XP-endo Shaper group, most cracks occurred in the middle area. All the cracks were of the incomplete type with the XP-endo Shaper system, but with the One-Shape system, $5 \%$ of the samples (3 sections) showed complete cracks.

\section{Acknowledgements:}

The support of the Vice-Chancellor for Research of the Faculty of Dentistry of Islamic Azad University of Medical Sciences, Tehran, Iran, is appreciated. It should be noted that this study is the result of a thesis with the design code of $25363 / \mathrm{t}$.

\section{References:}

1-Yoldas O, Yilmaz S, Atakan G, Kuden C, Kasan $Z$. Dentinal microcrack formation during root canal preparations by different NiTi rotary instruments and the self-adjusting file. J Endod. 2012 Feb;38(2):232-5. 2. Bier CA, Shemesh H, Tanomaru-Filho M, Wesselink PR, Wu MK. The ability of different nickel-titanium rotary instruments to induce dentinal damage during canal preparation. J Endod. 2009 Feb;35(2):236-8.

3. Shemesh H, Bier CA, Wu MK, Tanomaru-Filho M, Wesselink PR. The effects of canal preparation and filling on the incidence of dentinal defects. Int Endod J. 2009 Mar;42(3):208-13.

4. Adorno CG, Yoshioka T, Suda H. Crack initiation on the apical root surface caused by three different nickel-titanium rotary files at different working lengths. J Endod. 2011 Apr;37(4):522-5.

5. Liu R, Kaiwar A, Shemesh H, Wesselink PR, Hou $\mathrm{B}, \mathrm{Wu} \mathrm{MK}$. Incidence of apical root cracks and apical dentinal detachments after canal preparation with hand and rotary files at different instrumentation lengths. J Endod. 2013 Jan;39(1):129-32.

6. Tsesis I, Rosen E, Tamse A, Taschieri S, Kfir A. Diagnosis of vertical root fractures in endodontically treated teeth based on clinical and radiographic indices: a systematic review. J Endod. 2010 Sep;36(9):1455-8. 7. Kim HC, Lee MH, Yum J, Versluis A, Lee CJ, Kim 
BM. Potential relationship between design of nickeltitanium rotary instruments and vertical root fracture. J Endod. 2010 Jul;36(7):1195-9.

8. Nayak G, Singh I, Shetty S, Dahiya S. Evaluation of apical extrusion of debris and irrigant using two new reciprocating and one continuous rotation single file systems. J Dent (Tehran). 2014 May;11(3):302-9.

9. Bayram HM, Bayram E, Ocak M, Uygun AD, Celik HH. Effect of ProTaper Gold, Self-Adjusting File, and XP-endo Shaper Instruments on Dentinal Microcrack Formation: A Micro-computed Tomographic Study. J Endod. 2017;43(7):1166-69.

10. Eltit F, Ebacher V, Wang R. Inelastic deformation and microcracking process in human dentin. J Struct Biol. 2013 Aug;183(2):141-8.

11. Bechtle S, Fett T, Rizzi G, Habelitz S, Schneider GA. Mixed-mode stress intensity factors for kink cracks with finite kink length loaded in tension and bending: application to dentin and enamel. J Mech Behav Biomed Mater. 2010;3(4):303-12.

12. Paul RA, Tamse A, Rosenberg E. Cracked and broken teeth--definitions, differential diagnosis and treatment. Refuat Hapeh Vehashinayim (1993). 2007 Apr;24(2):7-12, 68 .

13. Rivera EM, Williamson A. Diagnosis and treatment planning: cracked tooth. J Tenn Dent Assoc. 2003 Spring;83(2):38-41.

14. Velozo C, Silva S, Almeida A, Romeiro K, Vieira B, Dantas H, et al. Shaping ability of XP-endo Shaper and ProTaper Next in long oval-shaped canals: a micro-computed tomography study. Int Endod J. 2020 Jul;53(7):998-1006.

15. Uğur Aydın Z, Keskin NB, Özyürek T. Effect of Reciproc blue, XP-endo shaper, and WaveOne gold instruments on dentinal microcrack formation: A micro-computed tomographic evaluation. Microsc Res Tech. 2019 Jun;82(6):856-860.

16. Milani AS, Froughreyhani M, Rahimi S, Jafarabadi MA, Paksefat S. The effect of root canal preparation on the development of dentin cracks. Iran Endod J. 2012 Fall;7(4):177-82.

17. Li SH, Lu Y, Song D, Zhou X, Zheng QH, Gao $\mathrm{Y}$, et al. Occurrence of Dentinal Microcracks in Severely Curved Root Canals with ProTaper Universal, WaveOne, and ProTaper Next File Systems. J Endod. 2015 Nov;41(11):1875-9.

18. Ashwinkumar V, Krithikadatta J, Surendran S, Velmurugan N. Effect of reciprocating file motion on microcrack formation in root canals: an SEM study. Int Endod J. 2014 Jul;47(7):622-7.

19. Reddy PJ, Kumar VS, Aravind K, Kumar HT, Vishal M B, Vizaikumar VN, et al. Canal shaping with one shape file and twisted files: a comparative study. J Clin Diagn Res. 2014 Dec;8(12):ZF01-3.

20. Soni D, Raisingani D, Mathur R, Madan N, Visnoi
S. Incidence of Apical Crack Initiation during Canal Preparation using Hand Stainless Steel (K-File) and Hand NiTi (Protaper) Files. Int J Clin Pediatr Dent. 2016 Oct-Dec;9(4):303-307.

21. Rivera EM, Walton RE. Longitudinal tooth fractures: findings that contribute to complex endodontic diagnoses. Endod Top. 2009;16:82-111.

22. Bürklein S, Tsotsis $P$, Schäfer E. Incidence of Dentinal Defects after Root Canal Preparation: Reciprocating versus Rotary Instrumentation. J Endod. 2013,39(4):501-4.

23. Liu R, Hou BX, Wesselink PR, Wu MK, Shemesh $H$. The incidence of root microcracks caused by 3 different single-file systems versus the ProTaper system. J Endod. 2013 Aug;39(8):1054-6.

24. Hin ES, Wu MK, Wesselink PR, Shemesh H. Effects of self-adjusting file, Mtwo, and ProTaper on the root canal wall. J Endod. 2013 Feb;39(2):262-4.

25. Aksoy Ç, Keriş EY, Yaman SD, Ocak M, Geneci F, Çelik HH. Evaluation of XP-endo Shaper, Reciproc Blue, and ProTaper Universal NiTi Systems on Dentinal Microcrack Formation Using Micro-Computed Tomography. J Endod. 2019 Mar;45(3):338-342. 26. Karataş E, Gündüz HA, Kırıcı DÖ, Arslan H, Topçu MÇ, Yeter KY. Dentinal crack formation during root canal preparations by the twisted file adaptive, ProTaper Next, ProTaper Universal, and WaveOne instruments. J Endod. 2015 Feb;41(2):261-4.

27. Garg S, Mahajan P, Thaman D, Monga P. Comparison of dentinal damage induced by different nickel-titanium rotary instruments during canal preparation: An in vitro study. J Conserv Dent. 2015 JulAug;18(4):302-5.

28. Soros C, Zinelis S, Lambrianidis T, Palaghias G. Spreader load required for vertical root fracture during lateral compaction ex vivo: evaluation of periodontal simulation and fracture load information. Oral Surg Oral Med Oral Pathol Oral Radiol Endod. 2008 Aug;106(2):e64-70.

29. Wilcox LR, Roskelley C, Sutton T. The relationship of root canal enlargement to finger-spreader induced vertical root fracture. J Endod. 1997 Aug;23(8):533-4. 30. Matsushita-Tokugawa M, Miura J, Iwami Y, Sakagami T, Izumi Y, Mori N, et al. Detection of dentinal microcracks using infrared thermography. J Endod. 2013 Jan;39(1):88-91.

cite this paper as: Mardani M, Hafezi L, Ghadimi

N. Calcifying Odontogenic Cyst Associated with Impacted Mandibular Canine: A Case Report. J Res Dent Maxillofac Sci. 2020;5(4):31-36 